\title{
An in vitro evaluation of turbulence after transcatheter aortic valve implantation
}

\author{
Hoda Hatoum, MS, ${ }^{\mathrm{a}}$ Atieh Yousefi, BS, ${ }^{\mathrm{a}}$ Scott Lilly, MD, PhD, ${ }^{\mathrm{b}}$ Pablo Maureira, MD, PhD,
} Juan Crestanello, MD, ${ }^{b}$ and Lakshmi P. Dasi, PhD ${ }^{a, b}$

\section{ABSTRACT}

Background: This study aimed at assessment of post-transcatheter aortic valve (TAV) replacement hemodynamics and turbulence when a same-size SAPIEN 3 (Edwards Lifesciences Corp, Irvine, Calif) and Medtronic Evolut (Minneapolis, Minn) were implanted in a rigid aortic root with physiological dimensions and in a representative root with calcific leaflets obtained from patient computed tomography scans.

Methods: TAV hemodynamics were studied by placing a SAPIEN $326-\mathrm{mm}$ and an Evolut 26-mm in rigid aortic roots and representative root with calcific leaflets under physiological conditions. Hemodynamics were assessed using high-fidelity particle image velocimetry and high-speed imaging. Transvalvular pressure gradients (PGs), pinwheeling indices, and Reynolds shear stress (RSS) were calculated.

Results: (1) PGs obtained with the Evolut and the SAPIEN 3 were comparable among the different models $(10.5 \pm 0.15 \mathrm{~mm} \mathrm{Hg}$ vs $7.76 \pm 0.083 \mathrm{~mm} \mathrm{Hg}$ in the rigid model along with $13.9 \pm 0.19 \mathrm{~mm} \mathrm{Hg}$ vs $5.0 \pm 0.09 \mathrm{~mm} \mathrm{Hg}$ in representative root with calcific leaflets obtained from patient computed tomography scans respectively); (2) more pinwheeling was found in the SAPIEN 3 than the Evolut $(0.231 \pm 0.057$ vs $0.201 \pm 0.05$ in the representative root with calcific leaflets and $0.366 \pm 0.067$ vs $0.122 \pm 0.045$ in the rigid model); (3) higher rates of RSS were found in the Evolut (161.27 \pm 3.45 vs $122.84 \pm 1.76 \mathrm{~Pa}$ in representative root with calcific leaflets and $337.22 \pm 7.05$ vs $157.91 \pm 1.80 \mathrm{~Pa}$ in rigid models). More lateral fluctuations were found in representative root with calcific leaflets.

Conclusions: (1) Comparable PGs were found among the TAVs in different models; (2) pinwheeling indices were found to be different between both TAVs; (3) turbulence patterns among both TAVs translated according to RSS were different. Rigid aortic models yield more conservative estimates of turbulence; (4) both TAVs exhibit peak maximal RSS that exceeds platelet activation $100 \mathrm{~Pa}$ threshold limit. (J Thorac Cardiovasc Surg 2018;156:1837-48)

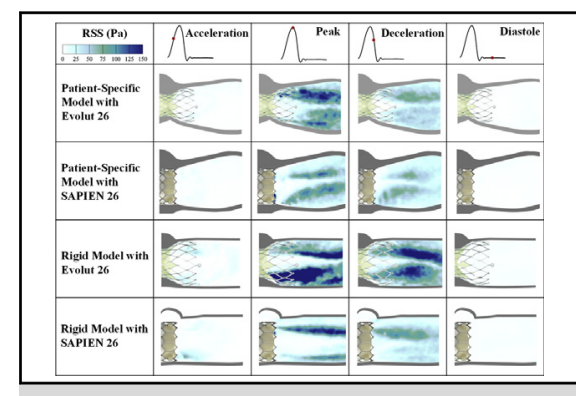

Principal Reynolds shear stresses at different phases in the cardiac cycle.

\section{Central Message}

Assessing hemodynamics and turbulence engendered after TAV replacement with different TAVs is important because it seeks to relate to platelet activation and thus thrombosis.

\section{Perspective}

TAVR is a less invasive technique to address aortic stenosis. Current shortcomings of TAVR include reduced leaflet mobility and limited long-term durability. In vitro hemodynamic assessment of TAVs indicated reduced Reynolds shear stress levels, significantly correlated to hemolysis. This observation is in agreement with recent clinical findings with TAVs.

See Editorial Commentary page 1849
From the Departments of ${ }^{\mathrm{a} B i o m e d i c a l}$ Engineering and ${ }^{\mathrm{b}}$ Surgery, The Ohio State University, Columbus, Ohio; and ${ }^{\mathrm{c}}$ Department of Cardiovascular Surgery, CHU de Nancy, Nancy, France.

This research was partly supported by the National Institutes of Health under award number R01HL119824.

Received for publication Oct 27, 2017; revisions received April 17, 2018; accepted for publication May 13, 2018; available ahead of print June 28, 2018

Address for reprints: Lakshmi P. Dasi, PhD, Department of Biomedical Engineering, The Ohio State University, 473 W 12th Ave, Columbus, OH 43210 (E-mail: lakshmi.dasi@osumc.edu).

$0022-5223 / \$ 36.00$

Copyright (c) 2018 by The American Association for Thoracic Surgery

https://doi.org/10.1016/j.jtcvs.2018.05.042
Transcatheter aortic valve (TAV) replacement (TAVR) emerged as a percutaneous alternative procedure for surgical aortic valve replacement procedures especially for high-risk patients. ${ }^{1,2}$ To date, all known heart valve prostheses have been associated with clinical complications and adverse effects resulting from

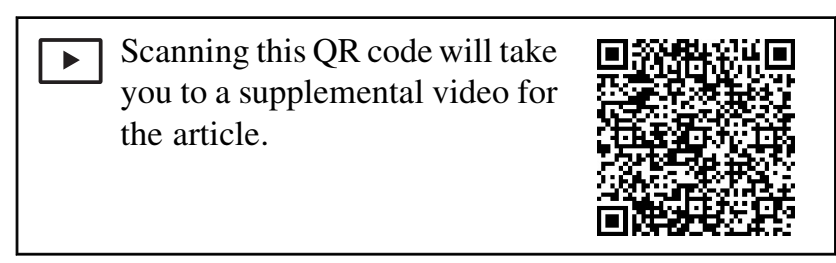




\section{Abbreviations and Acronyms \\ $\mathrm{CT}=$ computed tomography \\ $\mathrm{EOA}=$ effective orifice area \\ $\mathrm{PG}=$ pressure gradient \\ PI $=$ pinwheeling index \\ PIV $=$ particle image velocimetry \\ RSS $=$ Reynolds shear stress \\ $\mathrm{TAV}=$ transcatheter aortic valve \\ TAVR $=$ transcatheter aortic valve replacement \\ $\mathrm{TKE}=$ turbulent kinetic energy}

the nonphysiological flow patterns caused by their implantation. ${ }^{3,4}$ Elevated postprocedural pressure gradients (PGs), paravalvular leakage, TAV thrombosis, and many other degenerative effects particularly on the leaflets are some of these adverse outcomes. ${ }^{5}$ The relatively rapid degeneration of TAVs compromise their durability because of the mechanical forces exerted on the leaflets as they interact with the pulsatile blood flow and lead to having the patient go through another probable implantation. ${ }^{3,4,6}$

TAVs commonly used can be categorized into 2 distinct types: balloon-expandable, and self-expandable. Clinical studies have shown several significant differences between the 2 types, including significantly lower frequency of reduced leaflet motion with self-expandable TAVs such as CoreValve or Evolut (both from Medtronic, Minneapolis, Minn; 4\%-6\%) compared with $16 \%$ for balloonexpandable SAPIEN 3 (Edwards Lifesciences Corp, Irvine, Calif) ${ }^{7}$ while showing a significantly higher rate of moderate to severe paravalvular leakage, significantly greater need for permanent pacemaker implantation, and significantly lower radial force exerted by self-expandable TAVs. ${ }^{4,8-13}$ The distinct physical differences such as leaflet thickness, leaflet shape, stent frame curvature, and stent profile alters TAV hemodynamics and imposes limitations for both devices. ${ }^{14}$

Turbulence distal to heart valves during forward flow is the fundamental fluid dynamics phenomenon responsible for PG as well as hemolysis and platelet activation. It is a phenomenon fundamental to any fluid for which there is shearing (velocity changing significantly lateral to the direction of flow). Specifically turbulence occurs when the velocity is high enough that viscosity is unable to diffuse and damp any local fluctuations in velocity leading to an exponential rise of spatial and temporal fluctuations in velocity. These turbulent fluctuations in velocity lead to significantly strong shear stresses that blood cells and platelets experience compared with laminar flows ${ }^{15-17}$ and is dependent on the valve geometry (smoothness of inflow, stent elements, etc), leaflet performance (such as flutter), and distal diameter of the aorta relative to the valve orifice area. These turbulent stresses are referred to as Reynolds stresses and have been well known to correlate with hemolysis and platelet activation. Nonphysiological turbulent flow after valve implantation was associated with blood damage ranging from platelet activation (to probably thrombosis) and hemolysis. ${ }^{18-22}$ Several in vitro studies investigated the risk of platelet activation post-TAVR and set some thresholds that mark the onset of platelet activation from 10 to $100 \mathrm{~Pa}^{3,6,23-30}$ Some of these in vitro studies include Hung and colleagues, who reported platelet damage at 100 to 165 dynes $/ \mathrm{cm}^{2}$ with an exposure time of 102 seconds. ${ }^{31}$ Williams reported the onset of platelet activation at 130 dynes $/ \mathrm{cm}^{2}$ under an exposure time of 1023 seconds. ${ }^{32}$ Ramstack and colleagues reported that platelets are activated at 300 to 1000 dynes $/ \mathrm{cm}^{2}$ at an exposure time of 10 seconds. ${ }^{33}$ With all these data and keeping in mind the basic differences between the SAPIEN and the Evolut TAVs, it is thus crucial to assess the turbulence engendered after TAVR with these 2 distinct TAV types.

In this study, the turbulence engendered immediately downstream of a TAVR valve is evaluated when a SAPIEN and when a Medtronic Evolut are implanted in a rigid aortic root with physiological dimensions and in a calcified representative root with calcific leaflets obtained from patient computed tomography (CT) scans. The purpose of the latter is to assess the effect of more realistic deployment conditions for the 2 TAVs on the turbulence of the forward flow distal to the valves. To our knowledge no comparative study of in vitro leaflet kinematic assessment and Reynolds shear stress (RSS) characterization have been performed across different TAVs. Such a comparison is essential to improve future TAV designs and might provide a rationale behind adverse clinical outcomes. ${ }^{34-37}$

\section{METHODS}

\section{Valve Selection and Deployment}

To evaluate post-TAVR hemodynamics and turbulence using self-expanding and balloon-expandable TAVs, measurements described herein were conducted with a 26-mm Medtronic Evolut and a 26-mm Edwards SAPIEN 3 implanted in rigid aortic roots and representative root with calcific leaflets obtained from patient CT scans shown in Figure 1. The ascending diameter of the aorta in the rigid model was $31.75 \mathrm{~mm}$, which allows for the Evolut-with an upper part diameter of $32 \mathrm{~mm}$ - not to be compressed. The selection of the appropriate aortic root models matched each of the TAV sizes and was on the basis of the recommendations of Kasel and colleagues. ${ }^{38}$ Distensible extensions were added to the roots to connect to our experimental flow loop setup. Leaflet calcification is shown in Figure 1, $C$, and is used to assess the effect of calcification on the hemodynamic performance of the TAVs. Hatoum and colleagues $^{39}$ have detailed the patient-specific design.

\section{Hemodynamic Assessment}

Hemodynamic parameters were evaluated under pulsatile flow conditions created by a left heart simulator yielding physiological flow and pressure curves as previously described. ${ }^{40,41}$ The working fluid in this study was a blood analogue mixture of water and glycerine $(99 \%$ pure glycerine) producing a density of $1060 \mathrm{~kg} / \mathrm{m}^{3}$ and a kinematic viscosity of $3.5 \cdot 10^{-6} \mathrm{~m}^{2} / \mathrm{s}$. Sixty consecutive cardiac cycles of aortic 


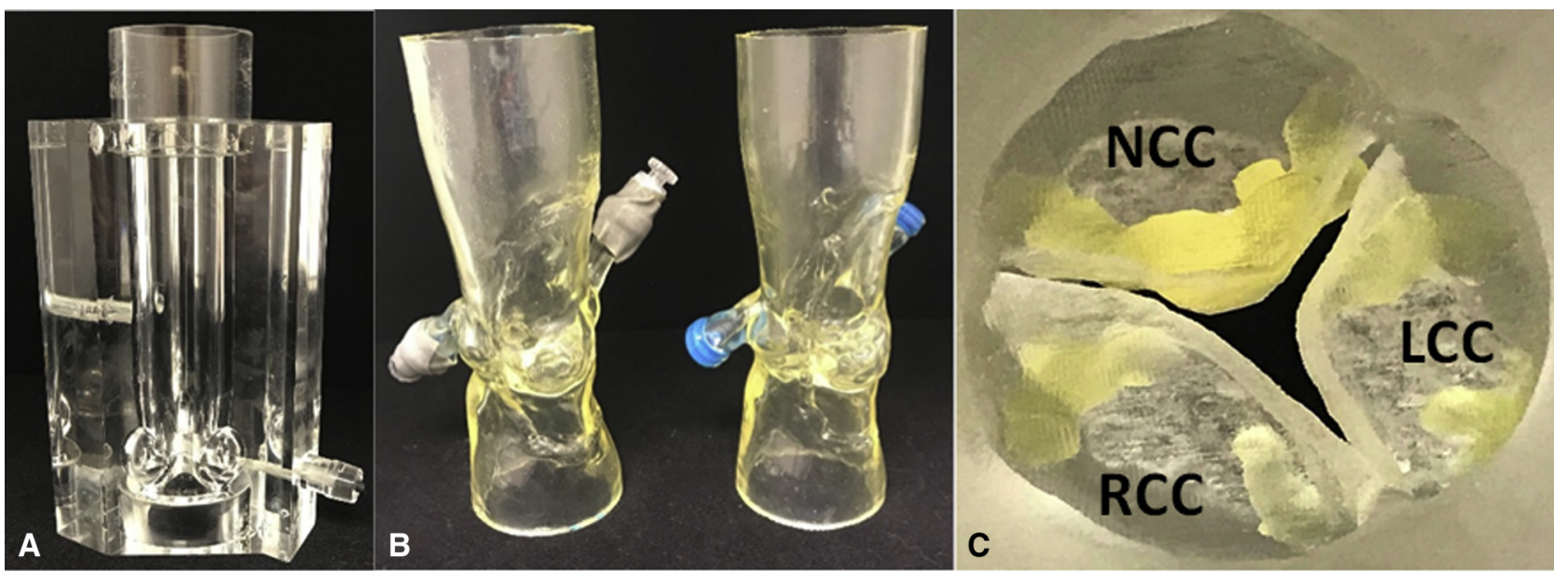

FIGURE 1. A, Rigid aortic valve chamber with sinuses. B, Patient-specific aortic root models with end extensions. C, Aortic side view of the 3-D printed leaflet calcifications in the patient-specific models. $N C C$, Noncoronary cusp; $L C C$, left coronary cusp; $R C C$, right coronary cusp.

pressure, ventricular pressure, and flow rate data were recorded at a sampling rate of $100 \mathrm{~Hz}$. The mean transvalvular PG is defined as the average of positive pressure difference between the ventricular and aortic pressure curves during forward flow.

The effective orifice area (EOA) is an important parameter to evaluate valve orifice opening. EOA was computed using the Gorlin's equation:

$$
E O A=\frac{Q}{51.6 \sqrt{P G}}
$$

where $\mathrm{Q}$ represents the root mean square aortic valve flow over the same averaging interval of the PG.

The pinwheeling index (PI) is an indication with implications on leaflet durability and resilience. ${ }^{42-44}$ It is computed from still frames obtained from high-speed imaging as follows and in accordance with Midha and colleagues $^{45}$ :

$$
P I=\frac{L_{\text {actual }}-L_{\text {ideal }}}{L_{\text {ideal }}}
$$

where $\mathrm{L}_{\text {actual }}$ represents the deflected free edge of the leaflet and $\mathrm{L}_{\text {ideal }}$ represents the unconstrained ideal configuration of the leaflet free edge.

\section{Particle Image Velocimetry}

For particle image velocimetry (PIV), the flow was seeded with fluorescent PMMA-Rhodamine B particles with diameters ranging from 1 to $20 \mu \mathrm{m}$. For all cases, the velocity fields within the distal flow region were measured using high spatial and temporal resolution PIV. Briefly, this involved illuminating the flow region using a laser sheet created by pulsed neodymium-doped yttrium lithium fluoride single-cavity diode pumped solid state laser coupled with external spherical and cylindrical lenses while acquiring high-speed images of the fluorescent particles within the region. Time-resolved PIV images were acquired with resulting spatial and temporal resolutions of $0.0723 \mathrm{~mm}$ per pixel and $1000 \mathrm{~Hz}$, respectively. Phase locked measurements were recorded for 4 phases of the cardiac cycle (acceleration, peak, deceleration, and diastole) repetitively 250 times with a spatial resolution of $0.0723 \mathrm{~mm}$ per pixel. Refraction was corrected using a calibration in DaVis PIV software (DaVis 7.2; Lavision, Göttingen, Germany). Velocity vectors were calculated using adaptive cross-correlation algorithms. Further details of PIV measurements can be found elsewhere. ${ }^{4,46}$

\section{Vorticity Dynamics}

Using the velocity measurements from PIV, vorticity dynamics were also evaluated distal to the valve. Vorticity is the curl of the velocity field and therefore captures rotational components of the blood flow shearing as well as visualizing turbulent eddies. Regions of high vorticity along the axis perpendicular to the plane indicate shear and rotation of the fluid particles. Vorticity was computed using the following equation:

$$
\omega_{z}=-\left(\frac{d V_{x}}{d y}-\frac{d V_{y}}{d x}\right)
$$

where $\omega_{\mathrm{z}}$ is the vorticity component with units of $\mathrm{s}^{-1} ; \mathrm{V}_{\mathrm{x}}$ and $\mathrm{V}_{\mathrm{y}}$ are the $\mathrm{x}$ and $\mathrm{y}$ components of the velocity vector with units of $\mathrm{m} / \mathrm{s}$. The $\mathrm{x}$ and $\mathrm{y}$ directions are axial and lateral, respectively, with the $\mathrm{z}$ direction being out of measurement plane.

\section{RSS and Turbulent Kinetic Energy}

RSS has been widely correlated to turbulence and platelet

\begin{tabular}{|c|c|c|c|c|c|c|}
\hline Valve type & Model type & $\Delta \mathrm{P}, \mathrm{mm} \mathrm{Hg}$ & EOA, $\mathrm{cm}^{2}$ & RF, \% & Pinwheeling index & Peak RSS, Pa \\
\hline \multirow{2}{*}{$\begin{array}{l}\text { Evolut (Medtronic, Minneapolis, } \\
\text { Minn) }\end{array}$} & Patient-specific & $13.9 \pm 0.19$ & $1.5 \pm 0.004$ & $32.10 \pm 0.70$ & $0.201 \pm 0.05$ & $161.27 \pm 3.45$ \\
\hline & Rigid & $10.5 \pm 0.15$ & $1.8 \pm 0.036$ & $15.74 \pm 0.73$ & $0.122 \pm 0.045$ & $337.22 \pm 7.05$ \\
\hline \multirow{2}{*}{$\begin{array}{l}\text { SAPIEN } 3 \text { (Edwards Lifesciences } \\
\text { Corp, Irvine, Calif) }\end{array}$} & Patient-specific & $5.0 \pm 0.09$ & $1.7 \pm 0.011$ & $23.75 \pm 0.75$ & $0.231 \pm 0.057$ & $122.84 \pm 1.76$ \\
\hline & Rigid & $7.76 \pm 0.083$ & $2.1 \pm 0.025$ & $10.92 \pm 0.11$ & $0.366 \pm 0.067$ & $157.91 \pm 1.80$ \\
\hline
\end{tabular}
activation. ${ }^{18,19}$ It is a statistical quantity that measures the shear stress

TABLE 1. Average hemodynamic parameters of the different valves

Values reported are \pm SD. $\triangle P$, Transvalvular pressure gradient (mm Hg); EOA, effective orifice area; $R F$, regurgitant fractions (\%); RSS, Reynolds shear stress. 


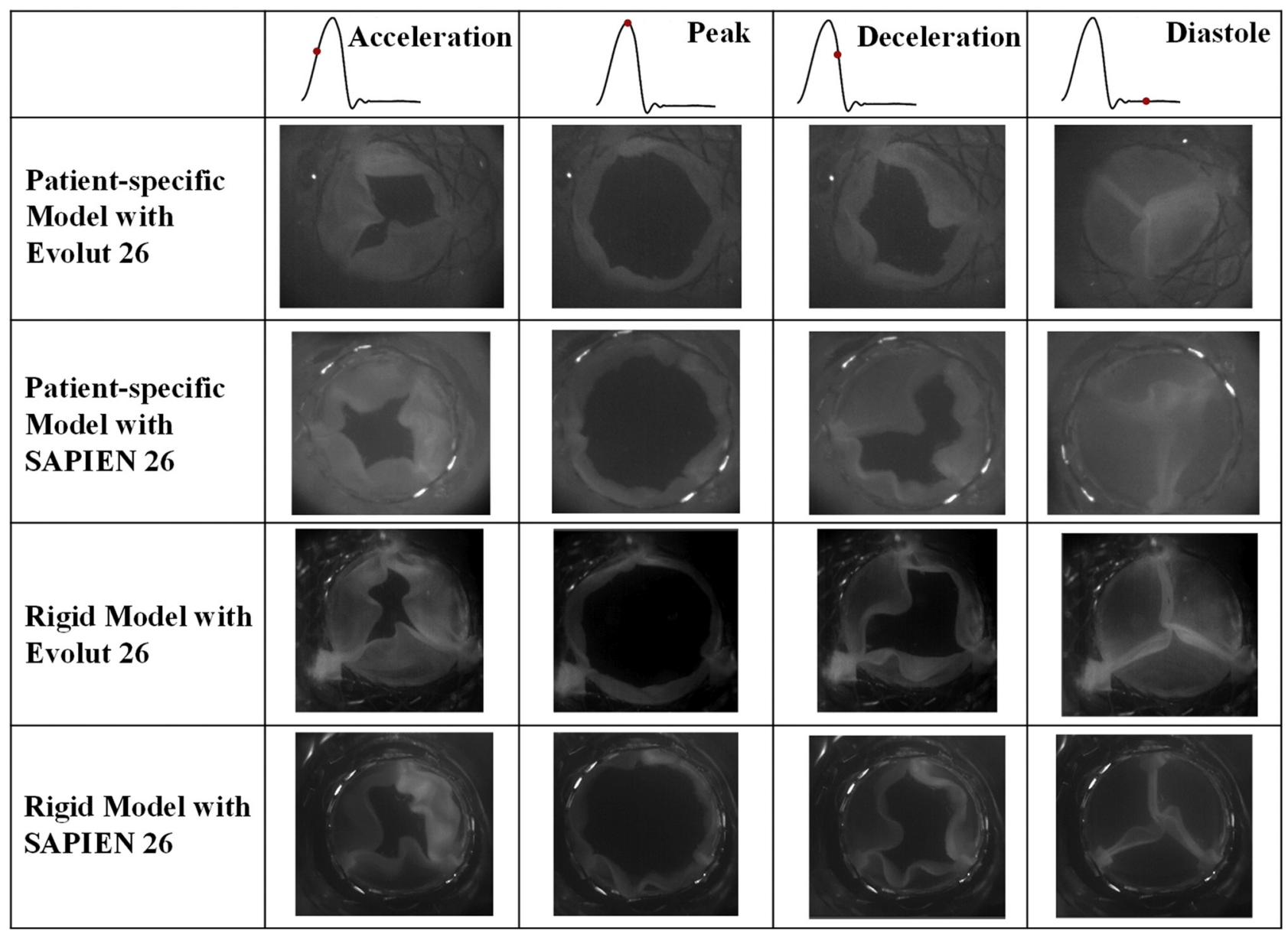

FIGURE 2. En face imaging of the valves at different phases in the cardiac cycle. The Evolut valve is from Medtronic (Minneapolis, Minn) and the SAPIEN valve is from Edwards Lifesciences Corp (Irvine, Calif).

between fluid layers when fluid particles decelerate or accelerate while changing direction. ${ }^{26}$ Turbulent kinetic energy (TKE) is a measurement of the kinetic energy of eddies and indicates turbulence intensity ${ }^{26}$ :

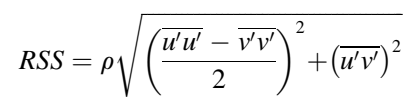

where $\rho$ is the blood density and $\mathrm{u}^{\prime}$ and $\mathrm{v}^{\prime}$ are the instantaneous velocity fluctuations in the $\mathrm{x}$ and $\mathrm{y}$ directions, respectively.

$$
T K E=\frac{1}{2}\left(\overline{u^{\prime 2}}+\overline{v^{\prime 2}}\right)
$$

\section{Statistics}

Statistical analysis in this study was performed using JMP Pro version 13.0.0 (SAS Institute Inc, Cary, NC). All data are presented as mean \pm standard error. Student $t$ test was used to compare the means and $P<.05$ was considered statistically significant. Analyses were performed over 60 replicates.

\section{RESULTS}

\section{Hemodynamic Parameters}

Table 1 shows hemodynamic parameters obtained from flow and pressure data for the different valves in the different models. In the rigid model, the Evolut yielded higher PG (10.5 $\pm 0.15 \mathrm{~mm} \mathrm{Hg})$ thus lower EOA $\left(1.8 \pm 0.036 \mathrm{~cm}^{2}\right)$ compared with the SAPIEN 3

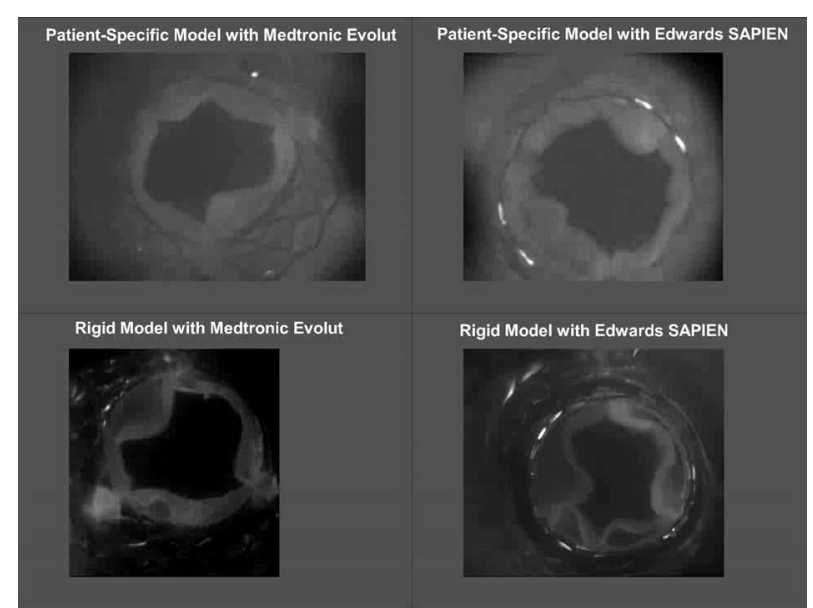

VIDEO 1. En-face imaging views of the valves throughout the cardiac cycle. Video available at: https://www.jtcvs.org/article/S0022-5223(18)31464-8/ fulltext. 


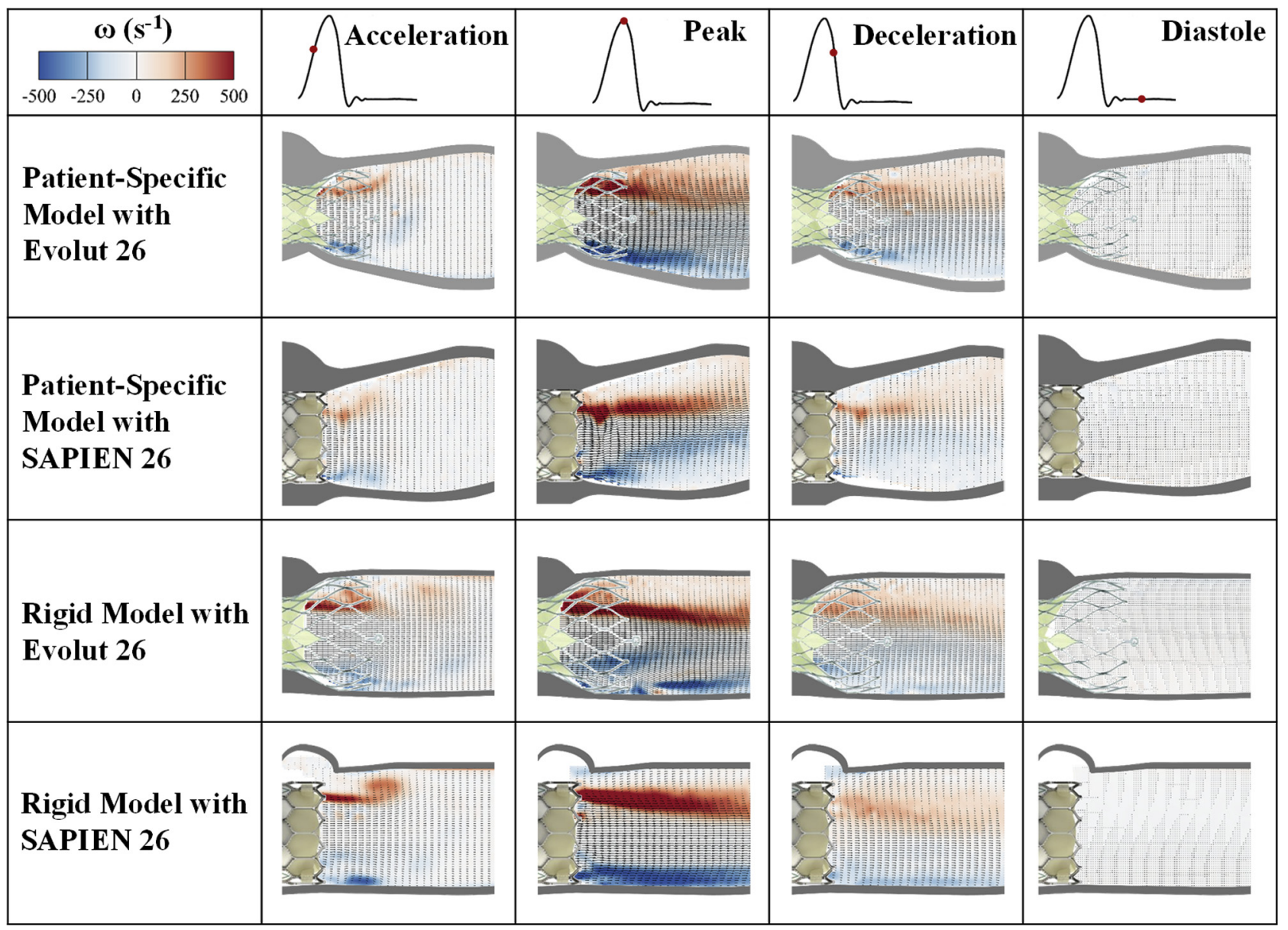

FIGURE 3. Phase averaged velocity vectors and vorticity contours at different phases in the cardiac cycle. The Evolut valve is from Medtronic (Minneapolis, Minn) and the SAPIEN valve is from Edwards Lifesciences Corp (Irvine, Calif).

$\left(7.76 \pm 0.083 \mathrm{~mm} \mathrm{Hg}\right.$ and $2.1 \pm 0.025 \mathrm{~cm}^{2}$, respectively; $P<.001)$. In the representative root with calcific leaflets model, similarly, the Evolut yielded higher PG $(13.9 \pm 0.19 \mathrm{~mm} \mathrm{Hg})$ thus lower EOA $\left(1.5 \pm 0.004 \mathrm{~cm}^{2}\right)$ compared with the SAPIEN $3(5.0 \pm 0.009 \mathrm{~mm} \mathrm{Hg}$ and $1.7 \pm 0.011 \mathrm{~cm}^{2}$, respectively; $\left.P<.001\right)$.

The Evolut and the SAPIEN 3 yielded different PGs in the representative root with calcific leaflets models compared with the rigid ones $(13.9 \pm 0.19 \mathrm{~mm} \mathrm{Hg}$ vs $10.5 \pm 0.15 \mathrm{~mm} \mathrm{Hg}$ for the Evolut and $5.0 \pm 0.09 \mathrm{~mm}$ $\mathrm{Hg}$ vs $7.76 \pm 0.083 \mathrm{~mm} \mathrm{Hg}$ for the SAPIEN; $P<.001)$.

\section{Leaflet Kinematics and PI}

Figure 2 shows en-face images of every valve in each of the representative root with calcific leaflets and rigid models at 4 phases of the cardiac cycle on the basis of flow: acceleration, peak, deceleration, and diastole. Video 1 shows the valve leaflets deformations and the significant central coaptation region twisting or pinwheeling. In the representative root with calcific leaflets model, the onset of the opening and the closure starts with 1 leaflet (bottom right leaflet) followed by the 2 others with the Evolut. However for the SAPIEN 3, the opening and closing mechanism is symmetrical. Both valves nevertheless fully open at peak systole. In the rigid model, the Evolut and the SAPIEN 3 open and close fully and symmetrically with all 3 leaflets together. In both models, the Evolut leaflets show more flutter compared with the SAPIEN 3.

The pinwheeling indices are shown in Table 1. The SAPIEN 3 showed higher pinwheeling indices in the representative root with calcific leaflets and rigid models compared with the Evolut $(0.231 \pm 0.057$ vs $0.201 \pm 0.05$ in the representative root with calcific leaflets model and $0.366 \pm 0.067$ vs $0.122 \pm 0.045$ in the rigid model). The coaptation mismatch in the SAPIEN 3 led to warping of the leaflets' edges. The Evolut yielded higher PI in the representative root with calcific leaflets model than in the rigid one $(0.201 \pm 0.05$ vs $0.122 \pm 0.045$ in the representative root with calcific leaflets model vs rigid one). However the differences were not significant $(P=.12)$. The SAPIEN 3, however, showed the opposite 


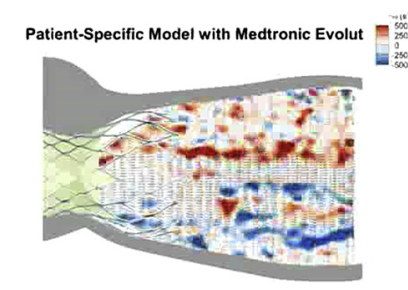

Patient-Specific Model with Edwards SAPIEN $=$

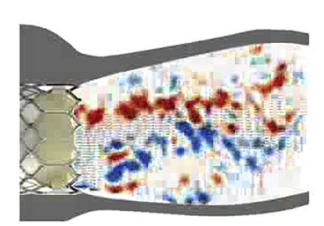

Rigid Model with Medtronic Evolut

Rigid Model with Edwards SAPIEN
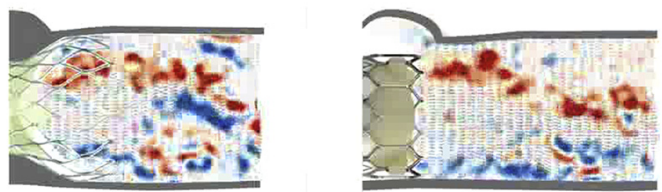

VIDEO 2. Ensemble averaged velocity vectors and vorticity contours for the valves. Video available at: https://www.jtcvs.org/article/S00225223(18)31464-8/fulltext.

$(0.231 \pm 0.057$ vs $0.366 \pm 0.067$ in the representative root with calcific leaflets model vs rigid one), although the differences were not significant $(P=.06)$.

\section{Flow Velocity Field}

Flow velocity field is an important indicator of the velocity and vorticity state of the flow highlighting high-velocity and high-rotation regions. The flow velocity field clearly shows the differences after implantation of many different TAVs. Because velocity is an important factor in evaluating post-TAVR dynamics clinically, velocity fields provide this comprehensive information. Figure 3 shows the phase averaged velocity vectors and vorticity contours at the 4 different phases in the cardiac cycle for the different valves and models. Video 2 shows an animation of the flow field development (vorticity contours and velocity vectors) throughout 1 cardiac cycle for each model and valve, and Video 3 shows the fluid particle streaks for every valve case in every model over the cardiac cycle. The dark streaks of red and blue vorticity contours represent the shear layers corresponding to the jet boundaries and the distance between them represents the width of the jet. Shear layers appear during the acceleration phase.

In a comparison of the representative root with calcific leaflets models, the velocity with the Evolut starts at $0.88 \mathrm{~m} / \mathrm{s}$ during acceleration to reach $2.3 \mathrm{~m} / \mathrm{s}$ at peak systole, then $1.3 \mathrm{~m} / \mathrm{s}$ during deceleration. With the SAPIEN 3 , the velocity starts at $0.46 \mathrm{~m} / \mathrm{s}$ during acceleration, reaches $1.65 \mathrm{~m} / \mathrm{s}$ at peak systole, then $0.62 \mathrm{~m} / \mathrm{s}$ during deceleration. The velocity is near 0 during diastole for both cases reaching a maximum of $0.2 \mathrm{~m} / \mathrm{s}$. It is clear that in the representative root with calcific leaflets models, the shear layers at peak systole diffuse laterally along the flow direction with more diffusion distal to the Evolut.

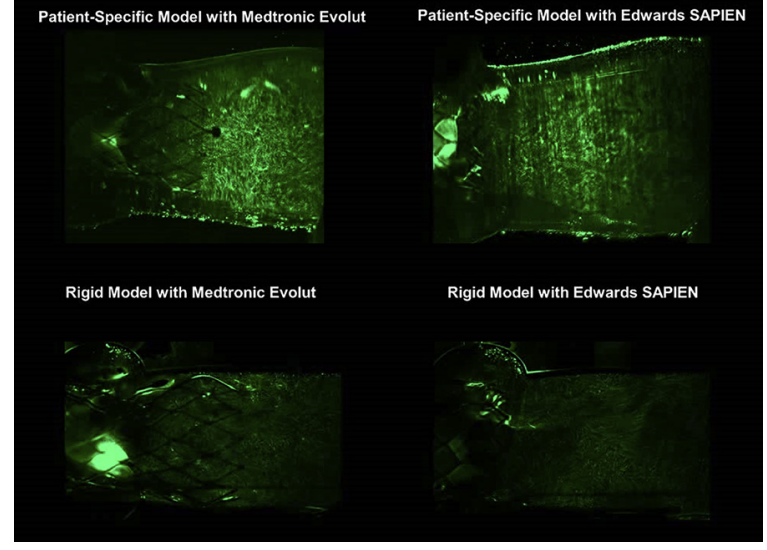

VIDEO 3. Main flow streak visualization of the different valves. Video available at: https://www.jtcvs.org/article/S0022-5223(18)31464-8/fulltext.

In a comparison of the rigid models, the velocity with the Evolut starts at $1.00 \mathrm{~m} / \mathrm{s}$ during acceleration to reach $2.45 \mathrm{~m} / \mathrm{s}$ at peak systole, then $1.37 \mathrm{~m} / \mathrm{s}$ during deceleration. With the SAPIEN 3, the velocity starts at $0.86 \mathrm{~m} / \mathrm{s}$ during acceleration, reaches $2.10 \mathrm{~m} / \mathrm{s}$ at peak systole, then $0.94 \mathrm{~m} / \mathrm{s}$ during deceleration. The velocity is near 0 during diastole reaching a maximum of $0.19 \mathrm{~m} / \mathrm{s}$ for both cases.

Compared with the representative root with calcific leaflets models, the shear layers and vortical structures in the rigid models with both valves exhibit a more stable and steady behavior especially during peak systole. Lateral turbulent diffusion, however, is more prevalent in the Evolut in accordance with the results observed in the representative root with calcific leaflets models. The peak vorticity was calculated to be 565 seconds $^{-1}$ for the Evolut in the representative root with calcific leaflets model, 668 seconds $^{-1}$ for the SAPIEN with representative root with calcific leaflets model, 676 seconds $^{-1}$ for the Evolut with the rigid model and 851 seconds $^{-1}$ for the SAPIEN with the rigid model. Parallelism of the shear layers (tendency of the shear layers to remain parallel to each other) is more maintained in the rigid models, particularly with the SAPIEN.

\section{RSS Fields}

The importance of RSS arises from its connection to platelet activation and its account of the turbulent fluctuations of the blood velocity. ${ }^{18-22}$ Figure 4 shows the principal RSSs at different phases in the cardiac cycle for the different valves and models. The contour plots of the RSS mirror those of the vortical shear layer structures in Figure 3 with RSS peaking in areas with more diffused shear layer vorticity.

The Evolut and the SAPIEN 3 valves exhibit higher RSS in the acceleration phase with the rigid model than the representative root with calcific leaflets model. Peak RSS in that phase reaches $46.05 \mathrm{~Pa}$ for the rigid model with Evolut and 59.9 Pa for the rigid model with SAPIEN. The 


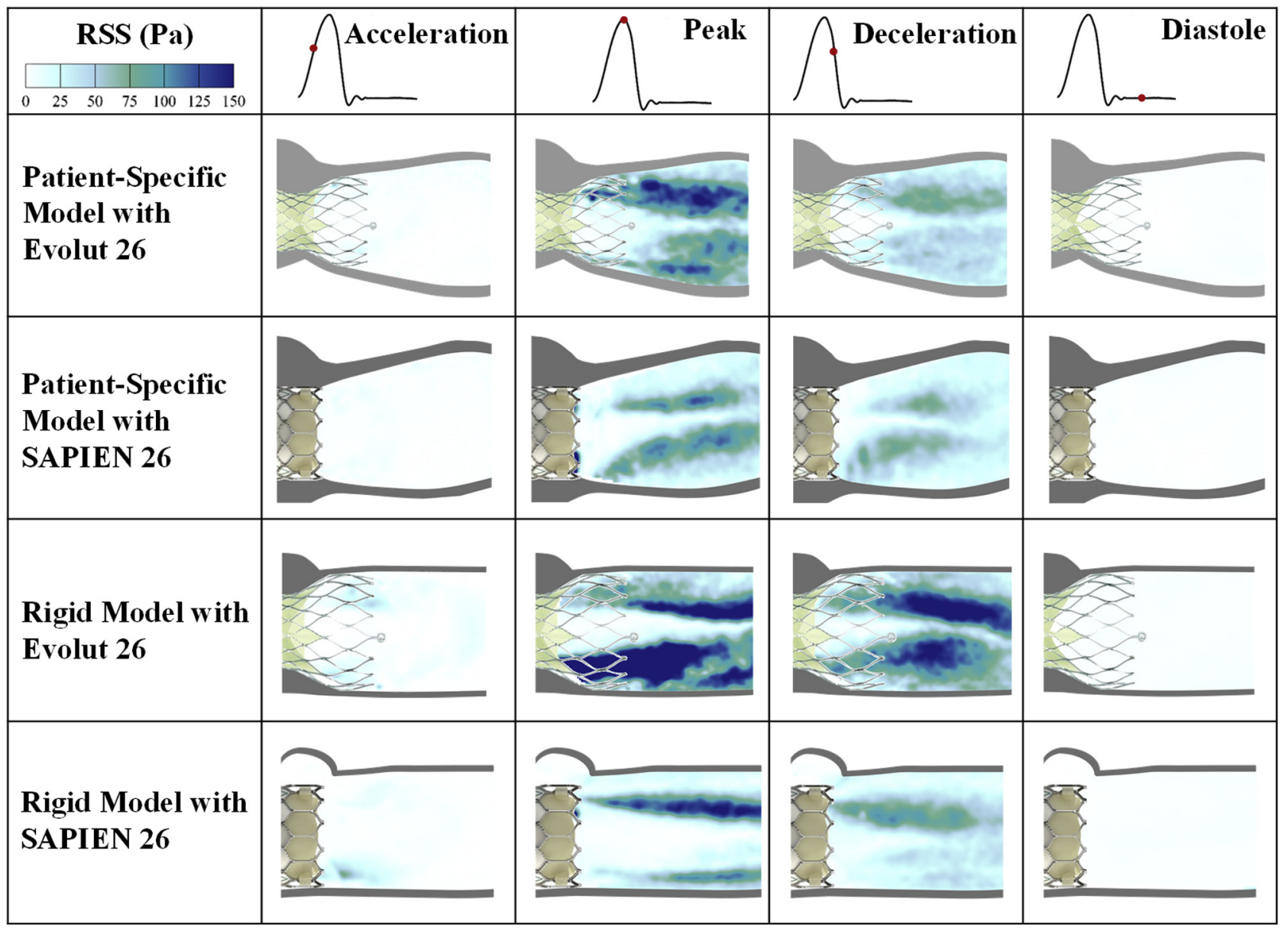

FIGURE 4. Principal Reynolds shear stress (RSS) at different phases in the cardiac cycle. The Evolut valve is from Medtronic (Minneapolis, Minn) and the SAPIEN valve is from Edwards Lifesciences Corp (Irvine, Calif).

RSS was calculated to be 9.40 and $8.87 \mathrm{~Pa}$ in the representative root with calcific leaflets model for Evolut and SAPIEN respectively.

During peak systole, the Evolut shows higher RSS distributions and magnitudes compared with the SAPIEN in representative root with calcific leaflets and rigid models. Table 1 shows the peak RSS values. In the representative root with calcific leaflets models, RSS were equal to 161.27 $\mathrm{Pa}$ and $122.84 \mathrm{~Pa}$ with the Evolut and SAPIEN, respectively. In the rigid model, RSS were equal to 337.22 $\mathrm{Pa}$ and 157.91 $\mathrm{Pa}$ with the Evolut and SAPIEN, respectively. It is also clear that the rigid models show higher RSS magnitudes with both valves.

After the peak, RSS decreases throughout deceleration and diastole. During deceleration, the maximum RSS obtained was with the Evolut in the rigid model (164.5 Pa).

\section{TKE}

TKE is the energy in velocity fluctuations and is dissipated by viscous forces through intense temporal events of blood shearing. It indicates how turbulent the blood flow is, thus giving an idea about the performance of the TAV implanted. TKE contour plots in Figure 5 mirror those of the RSS. Thus, the Evolut exhibits the highest TKE levels compared with the SAPIEN in both models particularly at peak systole. In the representative root with calcific leaflets model with Evolut, peak TKE was calculated to be $0.39 \mathrm{~m}^{2} / \mathrm{s}^{2}$ whereas the SAPIEN in the same model exhibited a TKE of $0.29 \mathrm{~m}^{2} / \mathrm{s}^{2}$. In the rigid model with Evolut, TKE was calculated to be $0.59 \mathrm{~m}^{2} / \mathrm{s}^{2}$ whereas the SAPIEN gave a value of $0.30 \mathrm{~m}^{2} / \mathrm{s}^{2}$.

\section{Turbulent Velocity Fluctuations}

Velocity fluctuations are characteristics of turbulent flow. These fluctuations give an indication about how turbulent the blood flow is thus providing an assessment of the TAV performance. Figure 6 shows the standard deviation contour plots of the turbulent velocity fluctuations $\mathrm{U}^{\prime}$ and $\mathrm{V}^{\prime}$ for the different valves and models at peak systole. As is the case for RSS and TKE, a large $\mathrm{U}^{\prime}$ root mean square (RMS) or $\mathrm{V}^{\prime}{ }_{\mathrm{RMS}}$ indicate a higher level of turbulence. $\mathrm{U}_{\mathrm{RMS}}^{\prime}$ and $\mathrm{V}_{\mathrm{RMS}}^{\prime}$ are highest with the Evolut in representative root with 


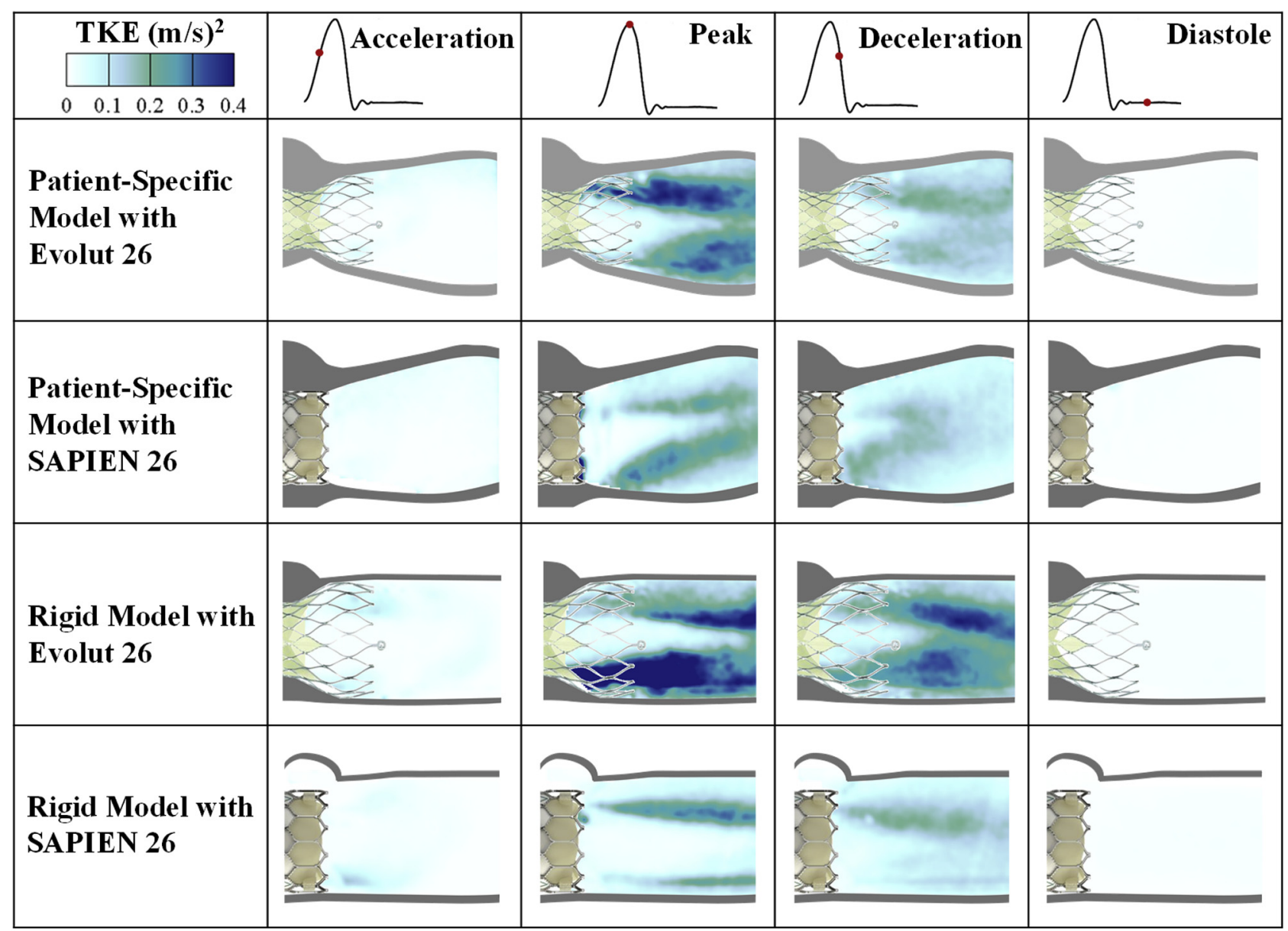

FIGURE 5. Turbulent kinetic energy (TKE) at different phases in the cardiac cycle. The Evolut valve is from Medtronic (Minneapolis, Minn) and the SAPIEN valve is from Edwards Lifesciences Corp (Irvine, Calif).

calcific leaflets and rigid models $(0.55 \mathrm{~m} / \mathrm{s}$ and $0.44 \mathrm{~m} / \mathrm{s}$ vs $0.76 \mathrm{~m} / \mathrm{s}$ and $0.51 \mathrm{~m} / \mathrm{s}$, respectively).

To better assess the turbulent velocity fluctuations, the instantaneous velocity taken at 2 different points (labeled $\mathrm{A}$ and $\mathrm{B}$ ) on the respective shear layers of the 4 valve cases are plotted versus the cardiac cycle time in the $\mathrm{x}$ and $\mathrm{y}$ directions. The plots are shown in Figure 7 and a summary of the values is given in Table 2. Time fluctuations are assessed in terms of the SDs of these plots and are associated with the degree of turbulence. The plots show clearly that at point $\mathrm{A}$, the rigid model with the Evolut valve shows more spread out fluctuations in the $\mathrm{x}$ direction (SD $0.58 \mathrm{~m} / \mathrm{s}$ ) and the representative root with calcific leaflets model with the Evolut shows more fluctuations in the $y$ direction (SD $0.194 \mathrm{~m} / \mathrm{s})$. At point B, the representative root with calcific leaflets model with Evolut shows higher fluctuations in the $\mathrm{x}$ and $\mathrm{y}$ directions $(0.752 \mathrm{~m} / \mathrm{s}$ and $0.211 \mathrm{~m} /$ $\mathrm{s}$, respectively). The fluctuations in the $\mathrm{y}$ direction are higher in the representative root with calcific leaflets models with both valves compared with those of the rigid models at points $\mathrm{A}$ and $\mathrm{B}$.

\section{DISCUSSION}

In this study, the differences engendered as a result of the 2 different TAVs (Evolut and SAPIEN) was assessed via: (1) hemodynamic parameters; and (2) turbulence in 2 different models, one rigid and another representative root with calcific leaflets. The importance of studying turbulence post-TAVR stems from its effect on platelet activation, hemolysis, and effects on pressure drop and recovery. Also, the importance of studying the idealized versus realistic aortic root is to assess how baseline design of these valves does not necessarily translate to the in situ setting.

\section{Effect of Anatomically Realistic Valve Mounting on Hemodynamic Parameters}

The different TAVs yielded different hemodynamic parameters specifically in terms of PGs. The most striking differences were seen between the representative root with calcific leaflets models and the rigid models with the main difference being that in the rigid model the valves were deployed in an idealistic manner and reached their full potential in an idealized circular orifice. However, in 


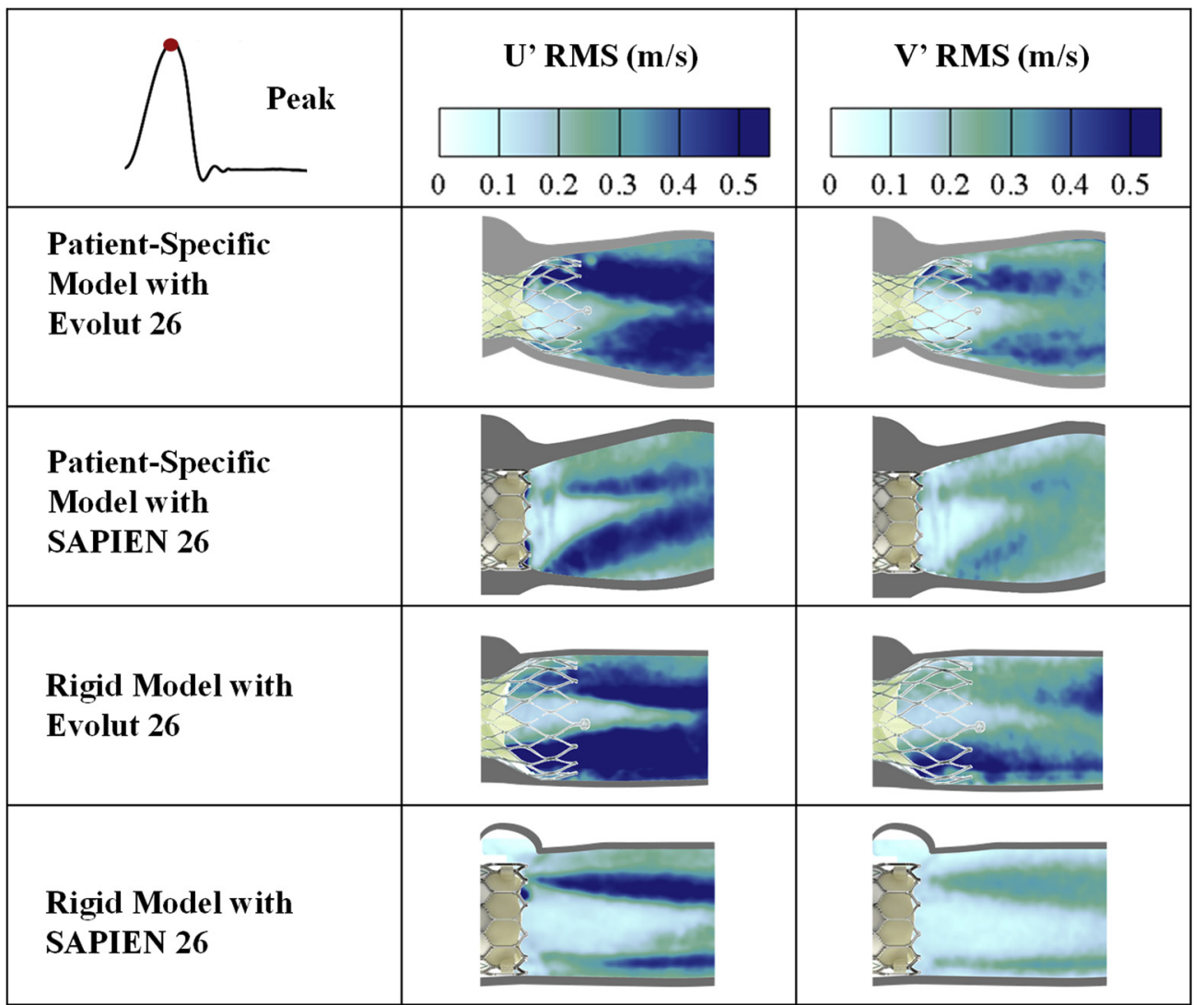

FIGURE 6. Standard deviation contour plots of the random velocity fluctuations U' and V' for the different valve models at peak systole. The Evolut valve is from Medtronic (Minneapolis, Minn) and the SAPIEN valve is from Edwards Lifesciences Corp (Irvine, Calif). RMS, Root mean square.

the representative root with calcific leaflets models the valves were deployed in an anatomically realistic configuration. The noncircular anatomy and calcification on and around the leaflets in the representative root with calcific leaflets models clearly play an important role in the apposition of the TAV, and thus its sealing., ${ }^{4,47,48}$ The leaflet stiffness in this model also plays a role in the valve shape post-deployment because a noncircular final shape might be a consequence, in addition to the distribution of the calcium adding to this stiffness and helping the noncircular and noncomplete apposition of the TAV. Because the SAPIEN is balloon-expandable, PGs were lower because the radial force exerted by the balloon gives the SAPIEN 3 an advantage in this case. ${ }^{4,47,48}$

\section{Leaflet Kinematics and PI}

PI is a dimensionless index used to quantify valve leaflet deformation severity and coaptation mismatch. High PIs are often associated with low durability, and therefore accelerated failure of valve leaflets. ${ }^{42-44}$ The SAPIEN showed higher pinwheeling indices than the Evolut in the representative root with calcific leaflets and rigid models. This might be because of the higher compression near the region of the leaflets in the SAPIEN compared with the supra-annular design of the Evolut in which stresses are not as much. ${ }^{44}$ Chakravarty and colleagues ${ }^{7}$ have shown in vivo data with more leaflet thrombosis prevalent in the SAPIEN than Evolut. In Video 1, it is clear that during peak flow, the SAPIEN 3 leaflets almost touch the stent inhibiting flow in the neosinus ${ }^{49}$ contrary to the Evolut, for which the supra-annular leaflet position along with the curved stent design allow for washout. It should be noted that pinwheeling is root and native valve calcium-induced geometry specific. The values shown in this study cannot be generalized and actual pinwheeling will be very patient-dependent. However, it is interesting that the SAPIEN valve pinwheeled more despite its advantage in orifice opening underpinning some fundamental design influences in how the leaflets are shaped and mounted in the 2 valves. Further studies are clearly needed to assess which valve is more "robust" to avoid pinwheeling. Pinwheeling is also dependent on the maximum expansion allowed and the extent of eccentricity of the orifice.

\section{Flow Velocity Field and Vorticity Dynamics}

The flow velocity fields and shear layers are different among the different valves and the models. The better apposition of the SAPIEN in the calcified aortic root as 

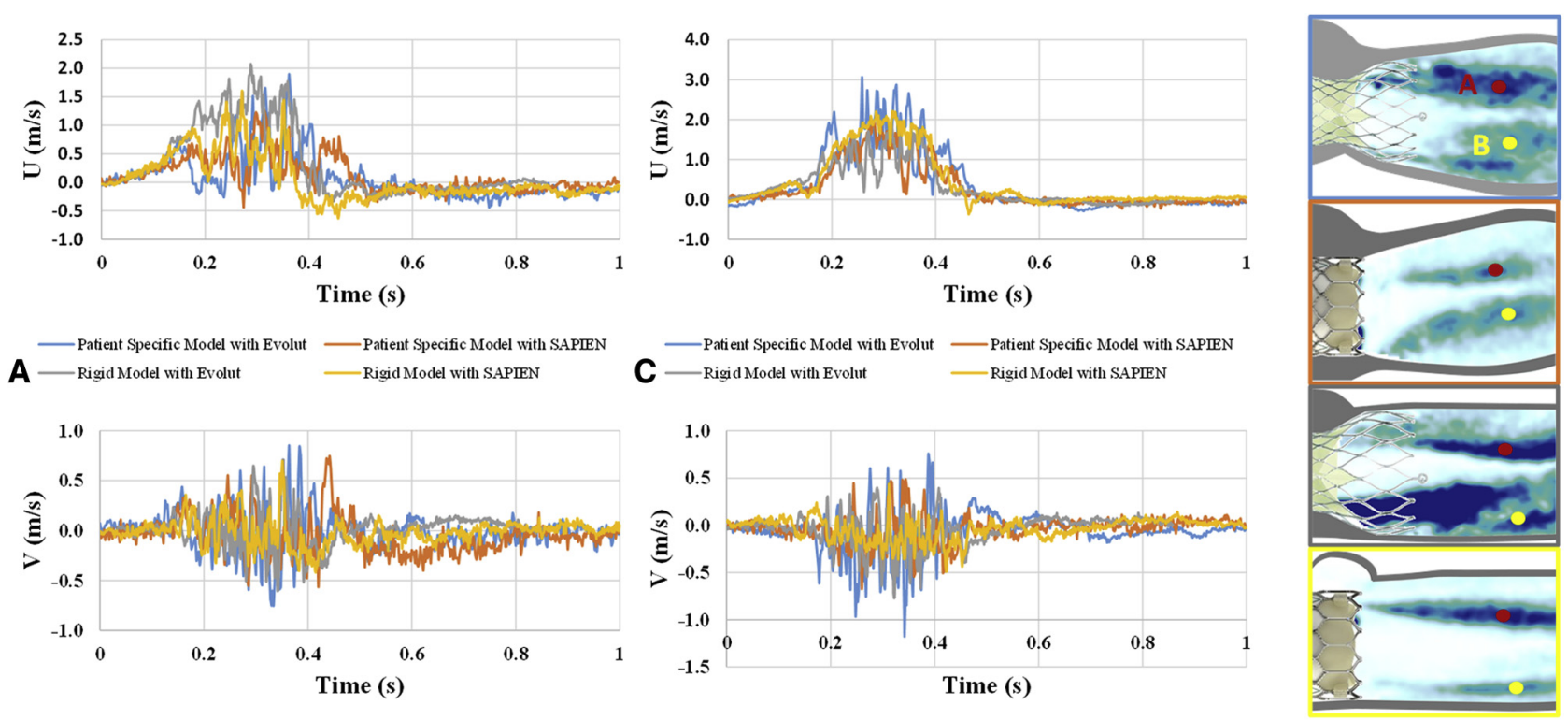

$\begin{array}{ll}\text { B } & \text { Patient Specific Model with Evolut } \\ \text { Rigid Model with Evolut } & \text { Patient Specific Model with SAPIEN }\end{array}$

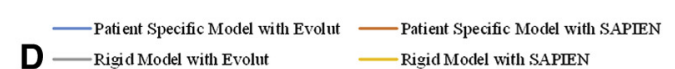

FIGURE 7. A and $\mathrm{C}$, Instantaneous velocity in the $\mathrm{x}$ direction $(U)$ and $(\mathrm{C})$ and $(\mathrm{D})$ instantaneous velocity in the y direction $(V)$ plots of the different valve combinations through the cardiac cycle at points (A and B), respectively, in the shear layers. The Evolut valve is from Medtronic (Minneapolis, Minn) and the SAPIEN valve is from Edwards Lifesciences Corp (Irvine, Calif).

previously explained provides more flow area thus lower jet velocity compared with the Evolut in the representative root with calcific leaflets models. In the rigid models, the SAPIEN yields lower velocities. This is in concordance with the PG data explained previously.

Turbulence is characterized by high levels of fluctuating vorticity. For this reason, vorticity dynamics play an essential role in the description of turbulent flows. ${ }^{50}$ Turbulent flows always exhibit high levels of fluctuating vorticity as is evident in Figure 3 contours and Video 2. In addition, shear layers in both TAVs seem to dissipate and to exhibit an unsteady behavior more quickly in the representative root with calcific leaflets models compared with the rigid ones. The reason behind that might be attributed to the flexible and more complex boundaries in the representative root with calcific leaflets models. In a

TABLE 2. SDs of the velocities in the $x$ and $y$ directions ( $U$ and $V$, respectively) at points $A$ and $B$ for the different valve combinations during the cardiac cycle

\begin{tabular}{cccccc}
\hline & \multicolumn{2}{c}{ Patient-specific model } & & \multicolumn{2}{c}{ Rigid model } \\
\cline { 2 - 3 } \cline { 5 - 6 } & Evolut & SAPIEN & & Evolut & SAPIEN \\
\hline SD, m/s & & & & \\
x direction & & & & \\
Point A & 0.389 & 0.303 & & 0.580 & 0.394 \\
Point B & 0.752 & 0.541 & & 0.522 & 0.750 \\
y direction & & & & \\
Point A & 0.194 & 0.187 & & 0.149 & 0.128 \\
Point B & 0.211 & 0.143 & 0.159 & 0.136 \\
\hline
\end{tabular}

The Evolut valve is from Medtronic (Minneapolis, Minn) and the SAPIEN valve is from Edwards Lifesciences Corp (Irvine, Calif). flexible medium, flow waves tend to be stabilized when the boundary has a compliant response to them but it was found that the effect of internal friction in the flexible medium might be destabilizing. ${ }^{51,52}$

\section{RSS Field}

The importance of RSS arises from its connection to platelet activation and its account of the turbulent fluctuations of the blood velocity. ${ }^{18-22}$ Reynolds stress is produced when fluid particles decelerate or accelerate while changing direction. ${ }^{22}$

The SAPIEN yielded lower RSS in representative root with calcific leaflets and rigid models compared with the Evolut, specifically at peak systole. This difference might be attributed to the distal meshed stent frame of the Evolut that protrudes along the sinotubular junction. Turbulence studies have emphasized the effect of porous media on increasing the flow turbulence, unsteadiness, and chaos. ${ }^{53,54}$ In addition, studies have shown that the presence of grids enhances turbulence, promotes rapid decay and diffusion axially, and increases skewness of the velocity fluctuation. ${ }^{55}$ This highlights the effect of the Evolut stent on the higher RSS calculated in the representative root with calcific leaflets and rigid models.

In addition, the representative root with calcific leaflets models provide lower RSS values compared with the rigid ones. The reason is because the compliant walls cause fluctuations thus dissipating RSS. ${ }^{51}$

On the basis of the peak RSS values calculated, it seems that both TAVs cross the threshold of $100 \mathrm{~Pa}$, defined as 
the onset of platelet activation, ${ }^{3,33,56}$ whether in the representative root with calcific leaflets or the rigid models, with the rigid models yielding more conservative-as in higher-estimates. The SAPIEN's peak values come in accordance with those found in a similar study by Gunning and colleagues. ${ }^{26}$ One in vitro study highlighted the effect of the SAPIEN structure on enhancing platelet activation and thus thrombus formation. ${ }^{57}$ Ultimately, because all cases exceed $100 \mathrm{~Pa}$, TAV leaflet thrombosis is dependent on many factors besides RSS, mainly sinus washout. ${ }^{41,58}$

\section{TKE and Velocity Fluctuations Effect}

TKE and $\mathrm{U}_{\text {RMS }}^{\prime}$ and $\mathrm{V}_{\mathrm{RMS}}^{\prime}$ are closely related as was introduced in the Methods. Because the velocity fluctuations in the $\mathrm{x}$ direction occur prevalently in both models with SAPIEN and Evolut TAVs, the main element of focus is the fluctuation in the lateral (y) direction. The fluctuations in the y direction are tightly related to the unsteadiness explained previously in the velocity and vorticity fields. Because in the representative root with calcific leaflets models unsteadiness prevails compared with the rigid models, it is intuitive to have high lateral direction fluctuations. Similarly, as discussed previously, the Evolut stent yields more unsteadiness causing the higher fluctuations with the Evolut than the SAPIEN. TKE contours reinforce these results. In addition, the more significant leaflet flutter observed in Video 1 with Evolut in both models comes in agreement with these lateral fluctuations and enhance the generated turbulence.

\section{Limitations}

The experiments conducted in this study investigated 2 distinct valves of the same size, $26 \mathrm{~mm}$ : a Medtronic Evolut and an Edwards SAPIEN. Although not anticipated, valve-to-valve variability (for the same size) is not addressed in this study. That said, the lack of a curved aorta is an additional limitation. Future studies are needed for capturing the influence of aortic curvature on any modification of turbulence distal to the valve. Another limitation might be related to the precise interaction between the valve stent and the 3-D printed native leaflets because there is large variability between patients in the stiffness of the leaflets. Short axis PIV is also lacking and studies using stereo capabilities or tomographic PIV systems are needed.

\section{CONCLUSIONS}

The hemodynamic performance and turbulence of two 26-mm TAVs (Medtronic Evolut and Edwards SAPIEN 3 ) in rigid and representative root with calcific leaflets obtained from patient CT scans models were assessed and compared in this study. The main hemodynamic parameters in terms of PGs were of the same order whereas pinwheeling indices were higher with the SAPIEN 3. The flow among both TAVs was different in terms of velocity fields, shear layer characteristics, RSS values, and contours along with velocity fluctuations. Whereas the SAPIEN 3 showed higher rates of pinwheeling, it was accompanied by lower rates of RSS compared with the Evolut because of the Evolut's distal stent structure interacting with the flow. Despite achieving less RSS, the SAPIEN still exhibited RSS that exceeds the threshold for platelet activation, which might explain the higher thrombosis risk found in vivo.

\section{Conflict of Interest Statement}

Dr Crestanello reports grants from Medtronic, Boston Scientific, and Abbot during the conduct of the study, and serves on the advisory board of Medtronic. Dr Dasi and Ms Yousefi report having 2 patent applications for The Ohio State University on novel surgical and transcatheter valves. All other authors have nothing to disclose with regard to commercial support.

\section{References}

1. Padala M, Sarin EL, Willis P, Babaliaros V, Block P, Guyton RA, et al. An engineering review of transcatheter aortic valve technologies. Cardiovasc Eng Tech nol. 2010;1:77-87.

2. Rodés-Cabau J. Transcatheter aortic valve implantation: current and future approaches. Nat Rev Cardiol. 2012;9:15.

3. Dasi LP, Simon HA, Sucosky P, Yoganathan AP. Fluid mechanics of artificial heart valves. Clin Exp Pharmacol Physiol. 2009;36:225-37.

4. Dasi LP, Hatoum H, Kheradvar A, Zareian R, Alavi SH, Sun W, et al. On the me chanics of transcatheter aortic valve replacement. Ann Biomed Eng. 2017;45: 310-31.

5. Mylotte D, Piazza N. Transcatheter aortic valve replacement failure: deja vu ou jamais vu? Circ Cardiovasc Interv. 2015;8:e002531.

6. Yoganathan AP, Chandran K, Sotiropoulos F. Flow in prosthetic heart valves: state-of-the-art and future directions. Ann Biomed Eng. 2005;33:1689-94.

7. Chakravarty T, Søndergaard L, Friedman J, et al. Subclinical leaflet thrombosis in surgical and transcatheter bioprosthetic aortic valves: an observational study Lancet. 2017;389:2383-92.

8. van der Boon RM, Van Mieghem NM, Theuns DA, Nuis R-J, Nauta ST, Serruys PW, et al. Pacemaker dependency after transcatheter aortic valve implan tation with the self-expanding Medtronic CoreValve system. Int J Cardiol. 2013; 168:1269-73.

9. Erkapic D, De Rosa S, Kelava A, Lehmann R, Fichtlscherer S, Hohnloser SH. Risk for permanent pacemaker after transcatheter aortic valve implantation: a comprehensive analysis of the literature. J Cardiovasc Electrophysiol. 2012; 23:391-7.

10. Steinberg BA, Harrison JK, Frazier-Mills C, Hughes GC, Piccini JP. Cardiac conduction system disease after transcatheter aortic valve replacement. Am Heart J. 2012;164:664-71.

11. Généreux P, Head SJ, Hahn R, Daneault B, Kodali S, Williams MR, et al. Paravalvular leak after transcatheter aortic valve replacement: the new Achilles' heel? A comprehensive review of the literature. J Am Coll Cardiol. 2013;61:1125-36.

12. Binder RK, Schäfer U, Kuck KH, Wood DA, Moss R, Leipsic J, et al. Transcatheter aortic valve replacement with a new self-expanding transcatheter heart valve and motorized delivery system. JACC Cardiovasc Interv. 2013;6:301-7.

13. Del Trigo M, Dahou A, Webb JG, Dvir D, Puri R, Abdul-Jawad Altisent O, et al Self-expanding Portico valve versus balloon-expandable SAPIEN XT valve in patients with small aortic annuli: comparison of hemodynamic performance. Rev Esp Cardiol (Engl Ed). 2016;69:501-8.

14. Fanning JP, Platts DG, Walters DL, Fraser JF. Transcatheter aortic valve implantation (TAVI): valve design and evolution. Int J Cardiol. 2013;168: 1822-31.

15. Morshed KN, Bark D Jr, Forleo M, Dasi LP. Theory to predict shear stress on cells in turbulent blood flow. PLoS One. 2014;9:e105357. 
16. Yun BM, Dasi L, Aidun C, Yoganathan A. Highly resolved pulsatile flows through prosthetic heart valves using the entropic lattice-Boltzmann method. J Fluid Mech. 2014;754:122-60.

17. Dasi LP, Morshed KN, Forleo M. Phenomenology of hemolysis in turbulent flows. ASME 2013 Summer Bioengineering Conference: American Society of Mechanical Engineers. 2013:1-20.

18. Giersiepen M, Wurzinger L, Opitz R, Reul H. Estimation of shear stress-related blood damage in heart valve prostheses-in vitro comparison of 25 aortic valves. Int J Artif Organs. 1990;13:300-6.

19. Nygaard H, Giersiepen M, Hasenkam J, Reul H, Paulsen PK, Rovsing PE, Westphal D. Two-dimensional color-mapping of turbulent shear stress distribution downstream of two aortic bioprosthetic valves in vitro. J Biomech. 1992; 25:437-40

20. Hanle D, Harrison E, Yoganathan A, Corcoran W. Turbulence downstream from the Ionescu-Shiley bioprosthesis in steady and pulsatile flow. Med Biol Eng Comput. 1987;25:645-9.

21. Schoephoerster RT, Chandran KB. Velocity and turbulence measurements past mitral valve prostheses in a model left ventricle. J Biomech. 1991;24: 549-62.

22. Jones SA. A relationship between Reynolds stresses and viscous dissipation: implications to red cell damage. Ann Biomed Eng. 1995;23:21-8.

23. Wurzinger L, Opitz R, Wolf M, Schmid-Schönbein H. "Shear induced platelet activation"-A critical reappraisal. Biorheology. 1985;22:399-413.

24. Claiborne TE, Slepian MJ, Hossainy S, Bluestein D. Polymeric trileaflet prosthetic heart valves: evolution and path to clinical reality. Exp Rev Med Dev. 2012;9:577-94.

25. Puri R, Auffret V, Rodés-Cabau J. Bioprosthetic valve thrombosis. J Am Coll Cardiol. 2017:69:2193-211.

26. Gunning PS, Saikrishnan N, McNamara LM, Yoganathan AP. An in vitro evaluation of the impact of eccentric deployment on transcatheter aortic valve hemodynamics. Ann Biomed Eng. 2014;42:1195-206.

27. Saikrishnan N, Gupta S, Yoganathan AP. Hemodynamics of the Boston Scientific Lotus ${ }^{\mathrm{TM}}$ valve: an in vitro study. Cardiovasc Eng Technol. 2013;4: 427-39.

28. Sutera SP. Flow-induced trauma to blood cells. Circ Res. 1977;41:2-8.

29. Alemu Y, Bluestein D. Flow-induced platelet activation and damage accumulation in a mechanical heart valve: numerical studies. Artif Organs. 2007;31:677-88.

30. Sirois E, Mao W, Li K, Calderan J, Sun W. Simulated transcatheter aortic valve flow: implications of elliptical deployment and under-expansion at the aortic annulus. Artif Organs. 2018;42:E141-52.

31. Hung T, Hochmuth R, Joist J, Sutera S. Shear-induced aggregation and lysis of platelets. ASAIO J. 1976;22:285-90.

32. Williams A. Release of serotonin from human platelets by acoustic microstreaming. J Acoust Soc Am. 1974;56:1640-3.

33. Ramstack J, Zuckerman L, Mockros L. Shear-induced activation of platelets. J Biomech. 1979;12:113-25.

34. Mack MJ, Leon MB, Smith CR, Miller DC, Moses JW, Tuzcu EM, et al. 5-year outcomes of transcatheter aortic valve replacement or surgical aortic valve replacement for high surgical risk patients with aortic stenosis (PARTNER 1): a randomised controlled trial. Lancet. 2015;385:2477-84.

35. Barbanti M, Petronio AS, Ettori F, Latib A, Bedogni F, De Marco F, et al. 5-year outcomes after transcatheter aortic valve implantation with CoreValve prosthesis. JACC Cardiovasc Interv. 2015;8:1084-91.

36. Webb J, Gerosa G, Lefèvre T, Leipsic J, Spence M, Thomas M, et al. Multicenter evaluation of a next-generation balloon-expandable transcatheter aortic valve. $J$ Am Coll Cardiol. 2014;64:2235-43.

37. Toggweiler S, Humphries KH, Lee M. 5-year outcome after transcatheter aortic valve implantation. J Am Coll Cardiol. 2013;61:413-9.

38. Kasel AM, Cassese S, Bleiziffer S, Amaki M, Hahn RT, Kastrati A, et al. Standardized imaging for aortic annular sizing. JACC Cardiovasc Imaging. 2013;6: 249-62.
39. Hatoum H, Dollery J, Lilly SM, Crestanello J, Dasi LP. Impact of patient-specific morphologies on sinus flow stasis in transcatheter aortic valve replacement: an in vitro study, J Thorac Cardiovasc Surg. June 7, 2018 [Epub ahead of print].

40. Forleo M. Dasi LP. Effect of hypertension on the closing dynamics and lagrangian blood damage index measure of the B-Datum Regurgitant Jet in a bileaflet mechanical heart valve. Ann Biomed Eng. 2014:42:110-22.

41. Hatoum H, Moore BL, Maureira P, Dollery J, Crestanello JA, Dasi LP. Aortic sinus flow stasis likely in valve-in-valve transcatheter aortic valve implantation. J Thorac Cardiovasc Surg. 2017;154:32-43.e1.

42. Martin C, Sun W. Simulation of long-term fatigue damage in bioprosthetic heart valves: effects of leaflet and stent elastic properties. Biomech Model Mechanobiol. 2014;13:759-70.

43. Doose C, Kütting M, Egron S, Farhadi Ghalati P, Schmitz C, Utzenrath M, et al. Valve-in-valve outcome: design impact of a pre-existing bioprosthesis on the hydrodynamics of an Edwards Sapien XT valve. Eur J Cardiothorac Surg. 2017;51: $562-70$

44. Gunning PS, Saikrishnan N, Yoganathan AP, McNamara LM. Total ellipse of the heart valve: the impact of eccentric stent distortion on the regional dynamic deformation of pericardial tissue leaflets of a transcatheter aortic valve replacement. J R Soc Interface. 2015;12:20150737.

45. Midha PA, Raghav V, Condado JF, Okafor IU, Lerakis S, Thourani VH, et al. Valve type, size, and deployment location affect hemodynamics in an in vitro valve-in-valve model. JACC: Cardiovasc Intervent. 2016;9:1618-28.

46. Hoda H, Dollery J, Lilly SM, Crestanello JA, Dasi LP. Effect of severe bioprosthetic valve tissue ingrowth and inflow calcification on valve-in-valve performance. J Biomech. 2018;74:171-9.

47. Bianchi M, Ghosh RP, Marom G, Slepian MJ, Bluestein D. Simulation of transcatheter aortic valve replacement in patient-specific aortic roots: effect of crimping and positioning on device performance. Engineering in Medicine and Biology Society (EMBC), 2015 37th Annual International Conference of the IEEE. 2015:282-285.

48. Morganti S, Conti M, Aiello M, Valentini A, Mazzola A, Reali A, et al. Simulation of transcatheter aortic valve implantation through patient-specific finite element analysis: two clinical cases. J Biomech. 2014;47:2547-55.

49. Midha PA, Raghav V, Sharma R, Condado JF, Okafor IU, Rami T, et al. The fluid mechanics of transcatheter heart valve leaflet thrombosis in the neo-sinus. Circulation. 2017;136:1598-609.

50. Laufer J. New trends in experimental turbulence research. Annu Rev Fluid Mech. 1975:7:307-26

51. Benjamin TB. Effects of a flexible boundary on hydrodynamic stability. J Fluid Mech 1960:9.513-32.

52. Landahl MT. On the stability of a laminar incompressible boundary layer over a flexible surface. J Fluid Mech. 1962;13:609-32.

53. Antohe B, Lage J. A general two-equation macroscopic turbulence model for incompressible flow in porous media. Int J Heat Mass Transf. 1997;40:3013-24.

54. Mößner M, Radespiel R. Flow simulations over porous media-comparisons with experiments. Comput Fluids. 2017;154:358-70.

55. Yang SK, Chung MK. Turbulent flow through spacer grids in rod bundles J Fluids Eng. 1998:120:786-91.

56. Liu J, Lu P, Chu S. Turbulence characteristics downstream of bileaflet aortic valve prostheses. J Biomech Eng. 2000;122:118-24.

57. Richardt D, Haban-Rackebrandt SL, Stock S, Scharfschwerdt M, Sievers HH. A matter of thrombosis: different thrombus-like formations in balloonexpandable transcatheter aortic valve prostheses. Eur J Cardiothorac Surg. 2018;54:157-61.

58. Hatoum H, Dollery J, Lilly SM, Crestanello JA, Dasi LP. Implantation depth and rotational orientation effect on valve-in-valve hemodynamics and sinus flow. Ann Thorac Surg. 2018;106:1-26.

Key Words: transcatheter aortic valve, turbulence, hemodynamics, platelet activation 